\title{
Influence of stored elastic strain energy on fatigue behaviour of NiTi shape memory alloy thermal actuator wire
}

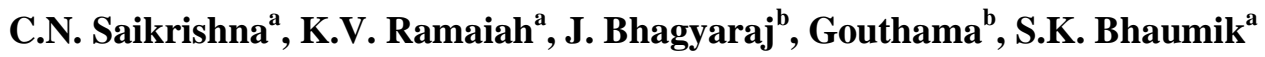 \\ ${ }^{a}$ Council of Scientific and Industrial Research, National Aerospace Laboratories, Bangalore 560017, India \\ ${ }^{b}$ Department of Materials Science and Engineering, Indian Institute of Technology, Kanpur, 208016, India
}

\begin{abstract}
Influence of stored elastic strain energy, $\mathrm{E}_{\text {else, }}$ on thermo-mechanical fatigue behaviour of NiTi shape memory alloy (SMA) thermal actuator wire was investigated. Two near equi-atomic NiTi SMA wires obtained from different sources were evaluated for quasi-static and functional fatigue properties. Study showed that the wires had similar chemical composition, transformation temperatures and static mechanical properties. However, the functional fatigue behaviour of the wires upon thermo-mechanical cycling (TMC) was found to be significantly different. Under a variable TMC stress in the range $150-450 \mathrm{MPa}$ and $4 \%$ recovery strain, one of the wires showed better stability, and substantially higher fatigue life $(\sim 30,000$ cycles) than the other ( $\sim 3,500$ cycles). Thermodynamic and microstructural analyses indicated that the wide variation in fatigue response of the wires was due to difference in magnitude of $E_{\text {else }}$ in the material. It is observed that at a given temperature above austenite start temperature $\left(\mathrm{A}_{\mathrm{s}}\right)$, the wire with higher stored $\mathrm{E}_{\text {else, }}$, generated about 70-100 MPa higher recovery stress than that of the wire with lower stored $\mathrm{E}_{\text {else. }}$ As a consequence, the maximum temperature, $T_{\max }$, necessary for generation of preset peak stress during reverse (martensite $\rightarrow$ austenite) transformation, was always less in the former wire than that of the latter. This in turn was responsible for wide variations in thermo-mechanical fatigue behaviour of the two wires upon TMC.
\end{abstract}

Keywords: Shape memory alloy; NiTi wire; elastic strain energy; functional fatigue

\section{INTRODUCTION}

Near equi-atomic NiTi shape memory alloys (SMAs) are potential candidate materials for use as solid-state thermal actuators in a variety of engineering and aerospace applications [1-2]. SMAs in service are required to perform large number of actuation cycles under cyclic thermomechanical loads and therefore, are subjected to fatigue. The fatigue behaviour in SMAs is complex and difficult to explain using conventional fatigue theories because of the phase transformation involved during cycling from martensite to austenite and vice-versa. The functional behaviour and fatigue life of SMAs depends on several factors such as alloy composition, thermo-mechanical processing history, stabilization treatment and stress-straintemperature regime of thermo-mechanical cycling [3-6].

NiTi alloys undergo thermoelastic martensitic transformation giving rise to its unique properties of shape memory effect and pseudoelasticity. The characteristics of thermoelastic martensitic transformation is the elastic accommodation of volume and shape change, that take place due to change in crystal structure upon phase transformation. The elastic strain energy associated with 
this accommodation process is stored in SMAs during forward transformation (austenite $\rightarrow$ martensite) and recovered during reverse transformation (martensite $\rightarrow$ austenite). The stored elastic strain energy, $\mathrm{E}_{\text {else }}$, in general, aids the reverse transformation and impedes the forward transformation. The effect of stored $\mathrm{E}_{\text {else }}$ on transformation behaviour of NiTi alloys has been studied extensively [7-11]. McCormick and Liu [7] reported that the changes in transformation temperatures of NiTi alloy during cycling are associated with the change in $\mathrm{E}_{\text {else }}$ and irreversible energy of phase transformation. The $\mathrm{E}_{\text {else }}$ was found to decrease with increase in number of thermal cycles under stress due to the formation of aligned martensite variants. In another study, Hamilton et al. [8] have shown that the transformation hysteresis in NiTi alloys increases with increase in external stress due to dissipation of stored $\mathrm{E}_{\text {else }}$ as a result of relaxation in coherency strains at martensite/austenite interfaces. Pelton et al. [9] studied the effect of stress-free thermal cycling on NiTi SMA and reported a decrease in martensite start temperature and increase in dislocation density from $\sim 10^{12} \mathrm{~m}^{-2}$ to $5 \times 10^{14} \mathrm{~m}^{-2}$ after 100 thermal cycles. The $\mathrm{E}_{\text {else }}$ and irreversible energy were found to increase with increase in number of thermal cycles. Salzbrenner and Cohen [10] showed that stored $E_{\text {else }}$ in SMAs was responsible for decrease in the transformation temperatures, and tilting of the transformation curves towards the left. These authors have also reported decrease in the transformation enthalpy with the increase in stored $\mathrm{E}_{\text {else }}$ in the material.

Since the use of SMA actuators involves repetitive transformation cycling, it is expected that $\mathrm{E}_{\text {else }}$ in the material would significantly affect the fatigue behaviour and performance. However, in spite of extensive studies on the role of $\mathrm{E}_{\text {else }}$ on the transformation behaviour, the literature on the effect of stored $E_{\text {else }}$ on the thermo-mechanical fatigue behaviour of SMAs is scant. The present study aims at investigating this aspect in NiTi SMA thermal actuators.

\section{EXPERIMENTAL PROCEDURE}

Two near equi-atomic NiTi wires of diameter $370 \mu \mathrm{m}$ obtained from different sources were used in this study. While the first wire (wire-1) was fabricated in author's laboratory, the second wire (wire-2) was obtained from a commercial source. The nominal alloy composition of the wires was determined using wave length dispersive spectroscopy (WDS) attached to Cameca make electron probe micro analyzer (EPMA, Model: SX 100). The transformation temperatures were determined using a TA make differential scanning calorimeter (DSC, Model: Q2000). The DSC scans were carried out at a heating/cooling rate of $10^{\circ} \mathrm{C} / \mathrm{min}$ under nitrogen atmosphere. The characteristic transformation temperatures, that is, martensite start $\left(\mathrm{M}_{\mathrm{s}}\right)$ and finish $\left(\mathrm{M}_{\mathrm{f}}\right)$, and austenite start $\left(A_{s}\right)$ and finish $\left(A_{f}\right)$ temperatures were determined from DSC curves using tangent method. The tensile properties of the wires were evaluated using Instron make table top universal testing machine (UTM) of $5 \mathrm{kN}$ capacity, fitted with environmental chamber (-100 to $\left.350^{\circ} \mathrm{C}\right)$. Wire samples of gauge length $30 \mathrm{~mm}$ were tested as per ASTM E8M standard at a strain rate of $2 \times 10^{-3} / \mathrm{s}$. Stress rate tests to determine the rate of recovery stress generated in the wires per degree rise in temperature was carried out by pre-straining the wire in martensite phase to $4 \%$ using UTM and then heating it in constrained condition. The stress generated in the wires for every 
$10^{\circ} \mathrm{C}$ rise in temperature was recorded. Transmission electron microscopy (TEM) study on the wires was carried out using FEI-Tecnai $\mathrm{G}^{2}$ U-Twin microscope operating at $200 \mathrm{kV}$. The details of sample preparation have been reported elsewhere [12].

Thermo-mechanical cycling (TMC) tests were carried out on wire samples of gauge length 150 $\mathrm{mm}$ under a variable bias stress of 100-450 MPa and 4\% recovery strain. The details of the test set-up can be found in ref. [6]. During TMC, the wires were resistive heated by passing direct current and cooled by natural air cooling. The current vs. time schedule of TMC is shown in Fig.1. The thermal cycling schedule was chosen such that maximum stress generated in the wires in high temperature austenite phase was $450 \mathrm{MPa}$. The temperature of the wires during TMC was determined separately by spot welding a ' $\mathrm{K}$ ' type thermocouple and thermal cycling the wire under similar stress/strain conditions. The wires were cycled till fracture and the variation in stress/strain with number of cycles were recorded. The two way shape memory strain (TWSMS) in the wires prior to TMC, was determined by subjecting the wires to TMC at a constant stress of $50 \mathrm{MPa}$. The difference in length of the wires in martensite and austenite phases determined from the transformation (strain vs. temperature) curve has been reported as TWSMS. The shift in austenite transformation temperatures under stress was determined using similar transformation curves, generated from TMC experiments at constant stresses ranging from 50-600 MPa.

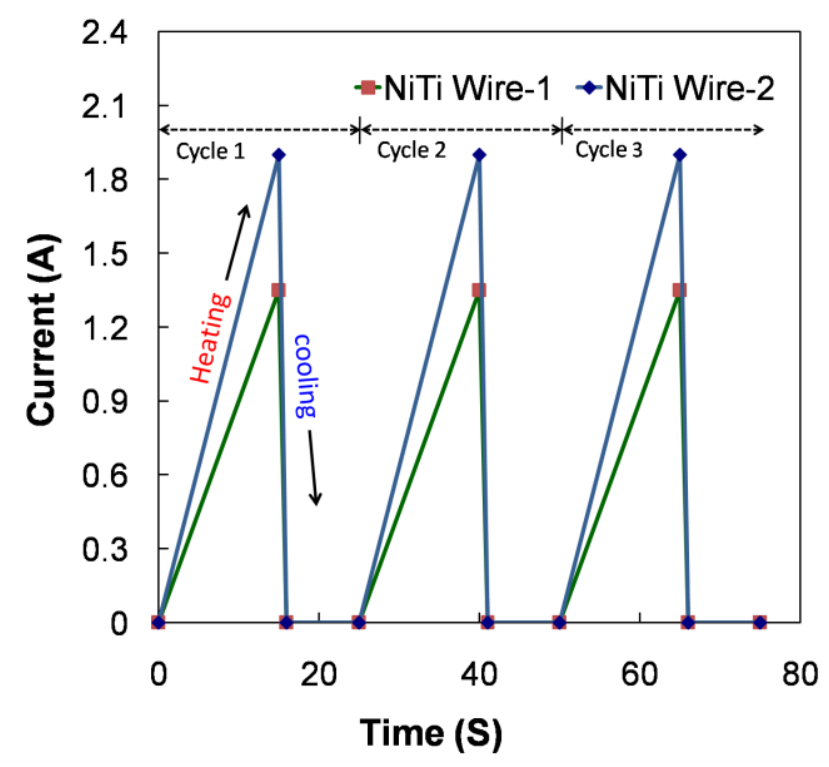

Figure 1 Current vs. time schedule used for heating and cooling of NiTi wires during TMC

\section{RESULTS}

Compositional analysis carried out using EPMA confirmed that nominal composition of the two wires used in this study is $49.8 \mathrm{Ni}-50.2 \mathrm{Ti}$ (at.\%). The DSC scans of the wires under stress-free condition are shown in Fig.2. It can be seen that the wires have more or less similar transformation behaviour except for diffused nature of peak in wire-1. The transformation temperatures are within $\pm 1^{\circ} \mathrm{C}$ with the exception of $\mathrm{M}_{\mathrm{f}}$, which is $19^{\circ} \mathrm{C}$ for wire- 1 and $25^{\circ} \mathrm{C}$ for 
wire-2 (Fig.2, Table 1). Further, the DSC scans show that the forward transformation in the wires is a two-step process. This two step transformation in binary NiTi SMAs, high temperature austenite (B2) transforming to low temperature martensite (B19') via R-phase, is well recognized [13]. The transformation hysteresis $\left(A_{f}-M_{s}\right)$ of the wires is found to be similar, in the range 30$31^{\circ} \mathrm{C}$ (Table 1).

Table 1Transformation temperatures of NiTi alloy wires in stress-free condition

\begin{tabular}{|c|c|c|c|c|c|c|}
\hline \multirow{2}{*}{ NiTi alloy } & \multicolumn{4}{|c|}{ Transformation Temperatures $\left({ }^{\circ} \mathrm{C}\right)$} & \multirow{2}{*}{$\begin{array}{l}\Delta \mathrm{H}^{\mathrm{a}-\mathrm{m}} \\
(\mathrm{J} / \mathrm{g})\end{array}$} & \multirow{2}{*}{$\begin{array}{l}\text { Hysteresis } \\
\qquad\left(\mathrm{A}_{\mathrm{f}}-\mathrm{M}_{\mathrm{s}}\right)\end{array}$} \\
\hline & $\mathrm{M}_{\mathrm{f}}$ & $\mathrm{M}_{\mathrm{s}}$ & $A_{s}$ & $A_{f}$ & & \\
\hline Wire-1 & 19 & 43 & 68 & 74 & 19.5 & 31 \\
\hline Wire-2 & 25 & 42 & 70 & 72 & 17.5 & 30 \\
\hline
\end{tabular}

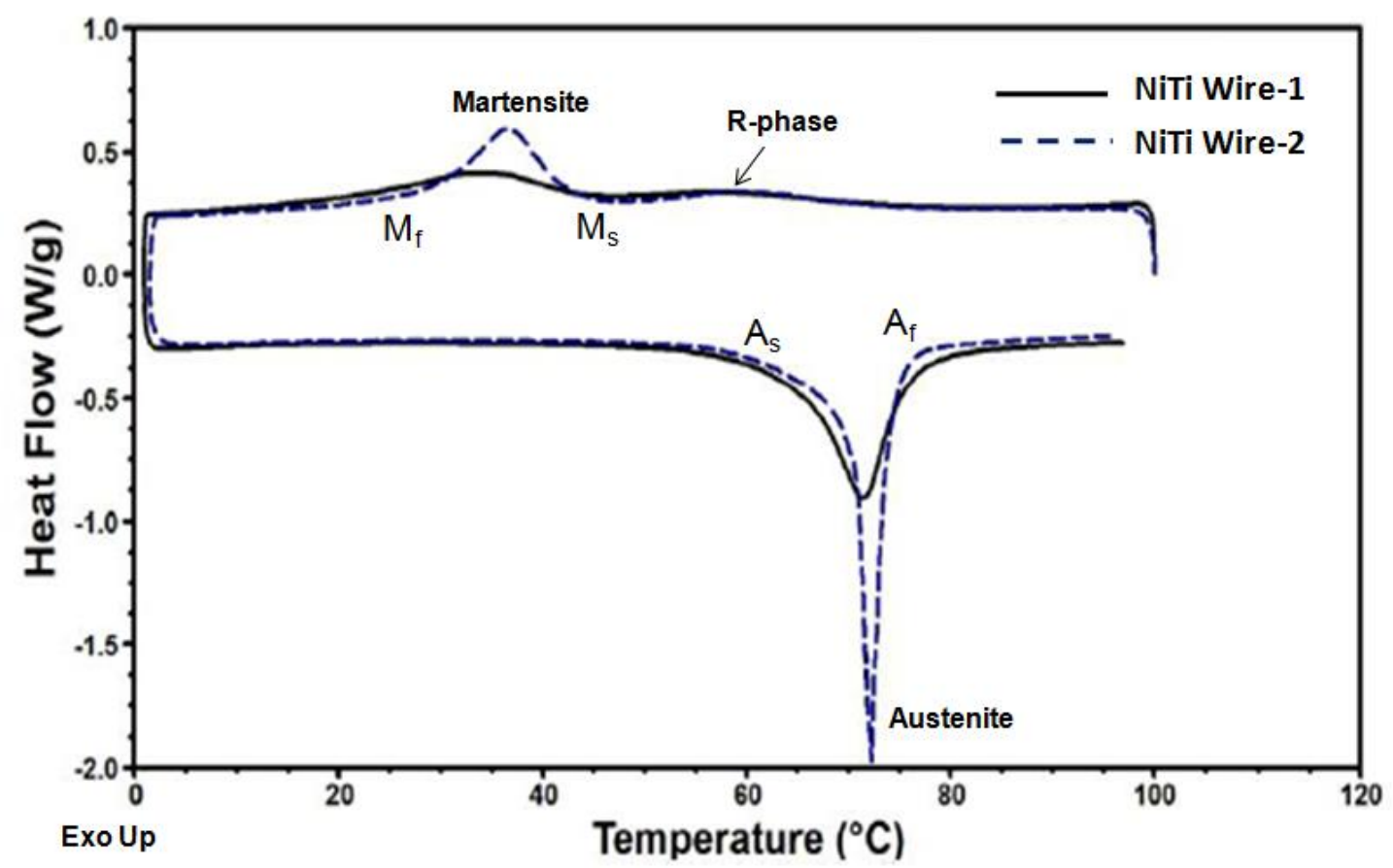

Figure 2 DSC scans showing the transformation behaviour of NiTi wires

Figure 3 shows stress-strain behaviour of the wires in martensite phase tested at ambient temperature $\left(23^{\circ} \mathrm{C}\right)$. The tensile strength and percent elongation to failure of the wires is found to be more or less similar, in the range $1390-1450 \mathrm{MPa}$ and $10.4-11.4 \%$ respectively. It is to be observed that the wires do not show the characteristic martensite stress plateau in the stress-strain plot and the stress increases monotonically up to fracture. 


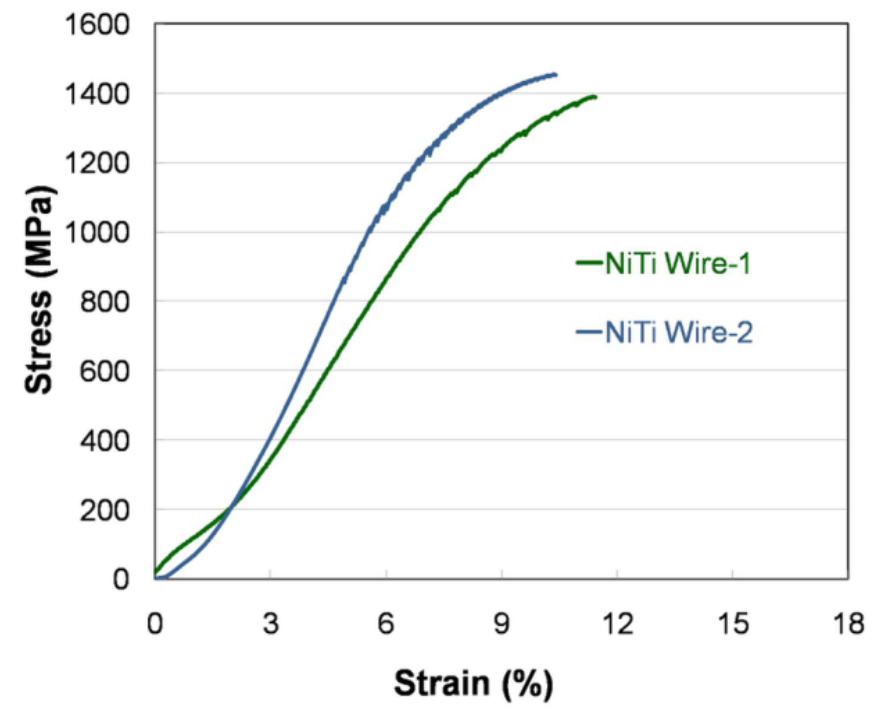

Figure 3 Stress vs. strain plot of NiTi wires in martensite phase

Figure 4 shows the recovery stress vs. temperature plot of the wires. The rate of recovery stress generation in the wires under constrained condition, stress rate, determined from the slope of the curve is marginally higher for wire- $1\left(7.4 \mathrm{MPa} /{ }^{\circ} \mathrm{C}\right)$ than that for wire-2 $\left(6.9 \mathrm{MPa} /{ }^{\circ} \mathrm{C}\right)$. Also, at a given temperature above $\mathrm{A}_{\mathrm{s}}$, recovery stress generation in wire-1 is about 70-100 MPa higher than that in wire-2. For example, at $115^{\circ} \mathrm{C}$, recovery stress generated in wire- 1 is $450 \mathrm{MPa}$ while it is $365 \mathrm{MPa}$ in wire- 2 . In other words, to attain a similar recovery stress of $450 \mathrm{MPa}$, wire-2 needs to be heated to a temperature of $130^{\circ} \mathrm{C}, 15^{\circ} \mathrm{C}$ higher than that of wire-1 (Fig.4). This requirement of differing peak temperature $\left(\mathrm{T}_{\max }\right)$ to achieve a given peak stress during TMC is

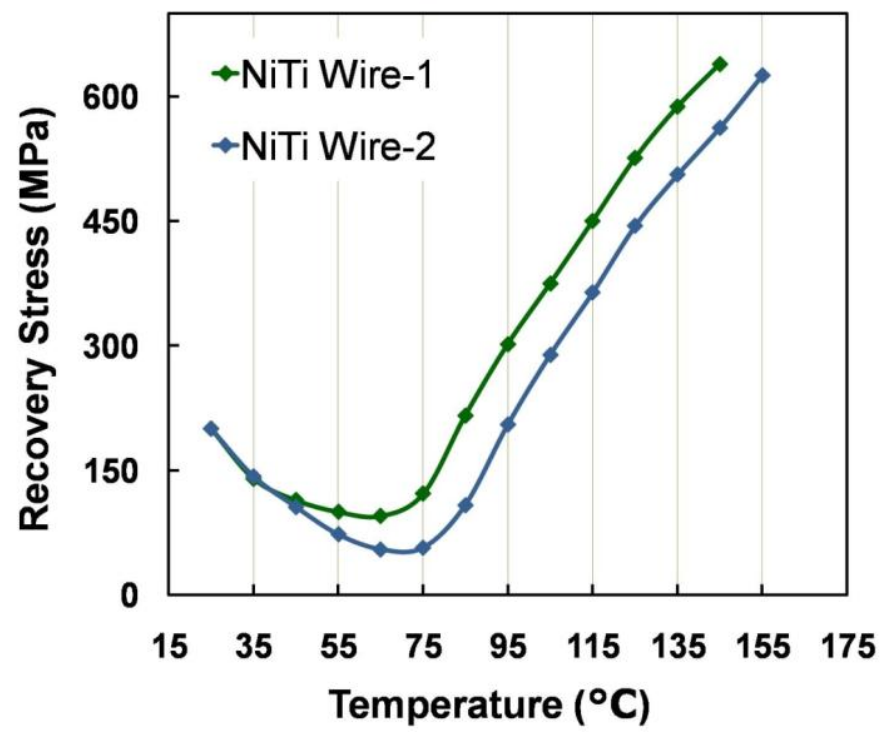

Figure 4 Stress vs. temperature plot shows the recovery stress generated after $4 \%$ pre-strain and heating in constrained condition. 


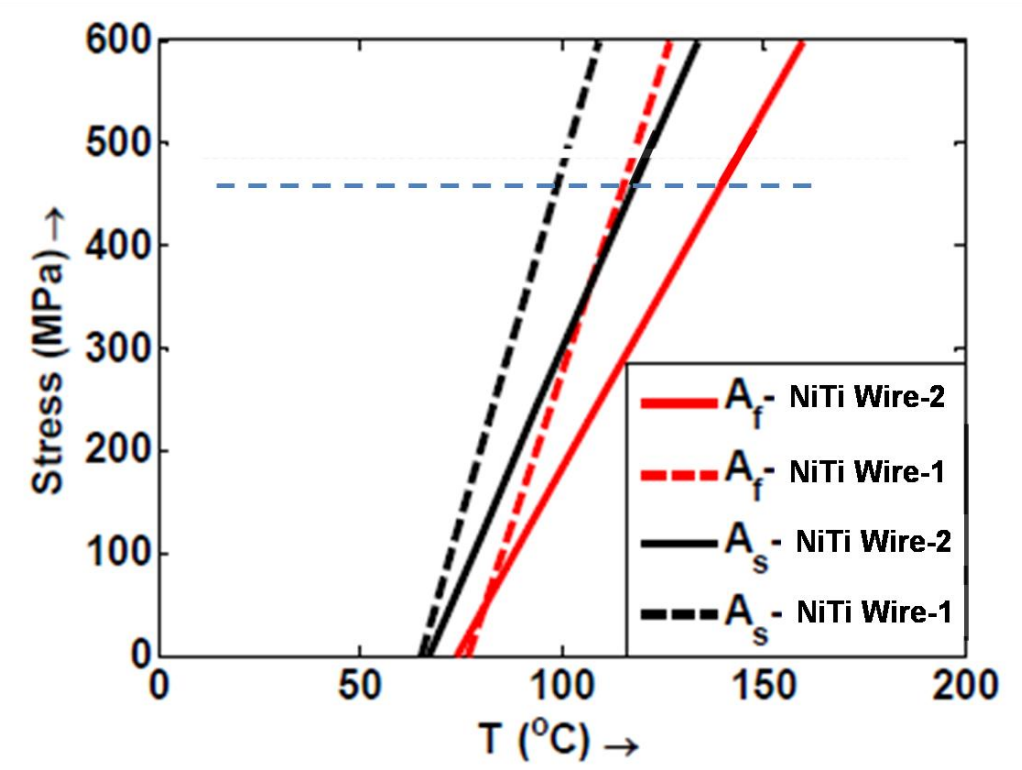

Figure 5 Stress vs. temperature plot of NiTi wires indicating austenite temperatures

also evident from stress dependence plot of $A_{s}$ and $A_{f}$ for the two wires (Fig.5). From the figure, it can be seen that although the wires have similar $A_{s}$ and $A_{f}$ in stress-free condition, the increase in these temperatures with stress is higher for wire- 2 than in wire- 1 . These results substantiate the requirement of different input current during the heating cycle of TMC for attaining the same peak stress (450 MPa) in the two wires (Fig. 1).

Figure 6 shows the functional fatigue behaviour of NiTi SMA wires cycled through complete transformation range (martensite $\leftrightarrow$ austenite). The experiments were conducted under a variable stress using a bias spring, wherein at the start of TMC, the stress in the wires in martensite and austenite phases were set to 150 and $450 \mathrm{MPa}$ respectively. The trend in variation in remnant deformation (RD) in the wires (Fig. 6(a)) is found to be typical of NiTi SMA thermal actuators. $\mathrm{RD}$ is defined as the accumulation of plastic strain in the material during TMC. The rate of change of RD is high during initial few hundred cycles, followed by a steady and monotonic increase. The cumulative value of RD for wire-1 at fracture is about $1 \%$ which is considerably lower than that of wire-2 (1.5\%). It is to be noted here that fracture life of wire-1 (30,000 cycles) is significantly higher than that of wire-2 (3,000 cycles). The variation in RS follows a similar trend as that of RD but in the reverse sense. The stresses in austenite and martensite phases of the wires are found to decrease with increase in cycles of TMC, the magnitude of decrease being significantly high in wire-2 than that in wire-1 (Fig.6(b)). The above results show that the wires have wide variation in functional fatigue properties. This is in spite of having similar composition, transformation temperatures and static mechanical properties. In view of this, further study was conducted on the wires to examine the possible reasons behind such differences in the functional fatigue behaviour. 

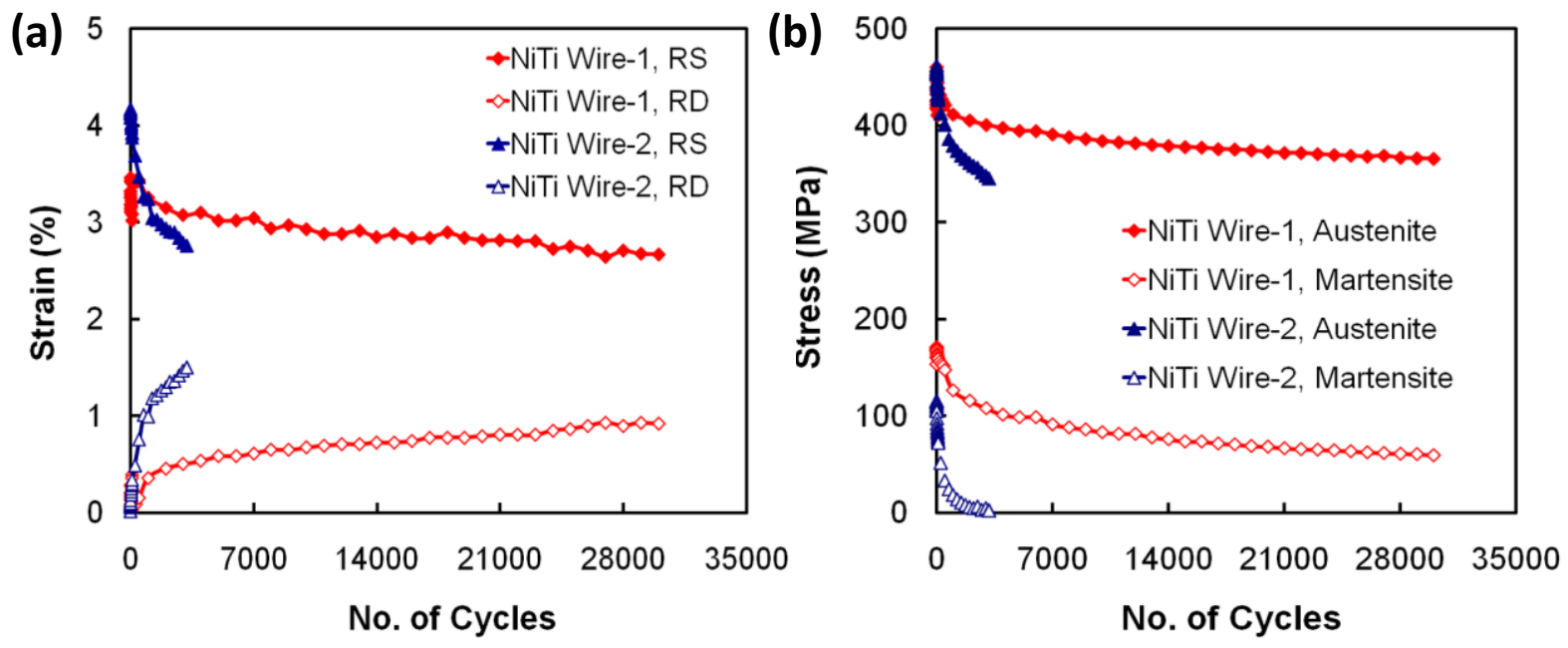

Figure 6 Thermo-mechanical cycling behaviour of NiTi wires under variable stress (a) strain vs. number of cycles (RS: recovery strain, RD: remnant deformation), (b) stress vs. number of cycles

The TWSMS in wire-1 and wire- 2 at ambient temperature, determined from the strain vs. temperature plot under constant stress of $50 \mathrm{MPa}$, is about 2.5 and $4.0 \%$ respectively (Fig.7). This stress of $50 \mathrm{MPa}$ is about $100-125 \mathrm{MPa}$ less than that required for detwinning to take place in martensite phase of the two wires (Fig.3). The $\mathrm{M}_{\mathrm{f}}$ measured from Fig.7 using tangent method is $20^{\circ} \mathrm{C}$ for wire- 1 and $30^{\circ} \mathrm{C}$ for wire-2. This agrees well with the DSC result wherein it is found that wire-1 requires significant under-cooling for complete transformation to martensite phase.

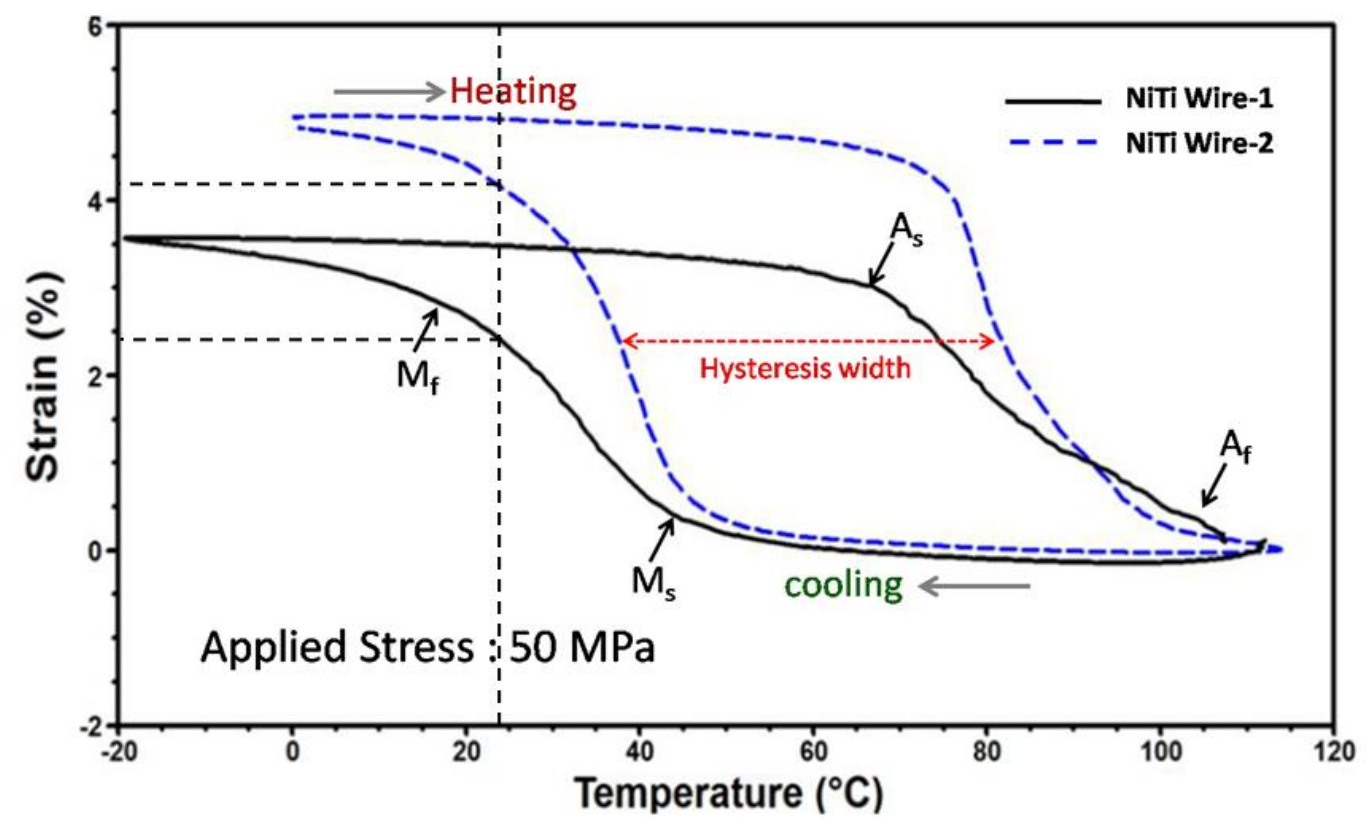

Figure 7 Strain vs. temperature plot of NiTi wire-1 and wire-2 upon TMC at $50 \mathrm{MPa}$. Black dotted lines indicates TWSMS at room temperature $\left(23^{\circ} \mathrm{C}\right)$ 
The transformation hysteresis represented by the width of transformation curve in Fig.7, is found similar for both the wires. But, the slope of transformation curves is significantly different, curve for wire-1 being tilted towards left with respect to that for wire-2. This observed difference in transformation behaviour is the manifestation of difference in magnitude of stored elastic strain energy in the wires $[8,11]$. In general, a higher stored elastic strain energy in the material results in a greater tilt in the transformation curve towards left. The magnitude of stored elastic strain energy in the wires is estimated using the following thermodynamic relations, provided in Ref. [7,9].

$$
\begin{aligned}
& \Delta \mathrm{E}_{\text {else }}{ }^{\mathrm{a}-\mathrm{m}}=\Delta \mathrm{S}\left(\mathrm{M}_{\mathrm{s}}-\mathrm{T}_{0}\right)-\Delta \mathrm{E}_{\mathrm{f}}^{\mathrm{a}-\mathrm{m}} \\
& \Delta \mathrm{E}_{\mathrm{f}}^{\mathrm{a}-\mathrm{m}}=\Delta \mathrm{S}\left[\left(\mathrm{M}_{\mathrm{s}}-\mathrm{A}_{\mathrm{s}}\right) / 2\right]
\end{aligned}
$$

where $\Delta \mathrm{E}_{\text {else }}{ }^{\mathrm{a}-\mathrm{m}}$ is the reversible elastic strain energy change in the material during forward transformation, $\Delta \mathrm{S}$ the change in chemical entropy $(\mathrm{J} / \mathrm{g} . \mathrm{K}) ; \mathrm{M}_{\mathrm{s}}$ the martensite start temperature $(\mathrm{K}), \mathrm{T}_{0}$ the equilibrium transformation temperature $(\mathrm{K})$, and $\Delta \mathrm{E}_{\mathrm{f}}^{\mathrm{a}-\mathrm{m}}$ the frictional work associated with movement of interfaces $(\mathrm{J} / \mathrm{g}) . \Delta \mathrm{S}$ and $\mathrm{T}_{0}$ are given by relations

$$
\Delta \mathrm{S}=\left(-\Delta \mathrm{H}^{\mathrm{a}-\mathrm{m}} / \mathrm{T}_{0}\right) \text { and } \mathrm{T}_{0}=\left(\mathrm{M}_{\mathrm{s}}+\mathrm{A}_{\mathrm{f}}\right) / 2
$$

where $\Delta \mathrm{H}^{\mathrm{a}-\mathrm{m}}$ is the enthalpy of forward transformation $(\mathrm{J} / \mathrm{g})$ and $\mathrm{A}_{\mathrm{f}}$ the austenite finish temperature $(\mathrm{K})$.

The values for $\Delta \mathrm{H}^{\mathrm{a}-\mathrm{m}}, \mathrm{M}_{\mathrm{s}}, \mathrm{M}_{\mathrm{f}}$ and $\mathrm{A}_{\mathrm{f}}$ for the wires are obtained from DSC scans (Table 1). Using Eq. 1 to Eq. 3, $\Delta \mathrm{E}_{\text {else }}$ for wire-1 and wire- 2 is calculated to be 0.176 and $0.053 \mathrm{~J} / \mathrm{g}$, respectively.

Figure 8 and 9 shows TEM bright field images and the corresponding SADP patterns for the wires prior to TMC. A comparative study of the microstructures suggests that lattice strain/distortion in wire-1 is more than that in wire-2 (Figs.8(a) and 9(a)). This is evident from non-uniform contrast observed in the dark regions of the micrograph in Fig.8(a). Further, the SADP pattern of wire-1 shows azimuthal spreading and diffused intensity of diffraction spots compared to that of wire-2, indicative of high degree of lattice strain in the material [14]. Another interesting aspect to note from the patterns is that wire-1 shows relatively moderate texture compared to that of wire-2. This is clear from the random clustering of diffraction spots observed in wire-1 (Fig.8(b)) compared to that of wire-2 (Fig.9(b)) which shows strong localization of intensity along $\langle 111\rangle$. Significant differences in the grain/variant size can also be observed from the high magnification images of the two wires (Figs.8(c) and 9(c)), with wire-1 having a relatively lower grain size of $<50 \mathrm{~nm}$. 


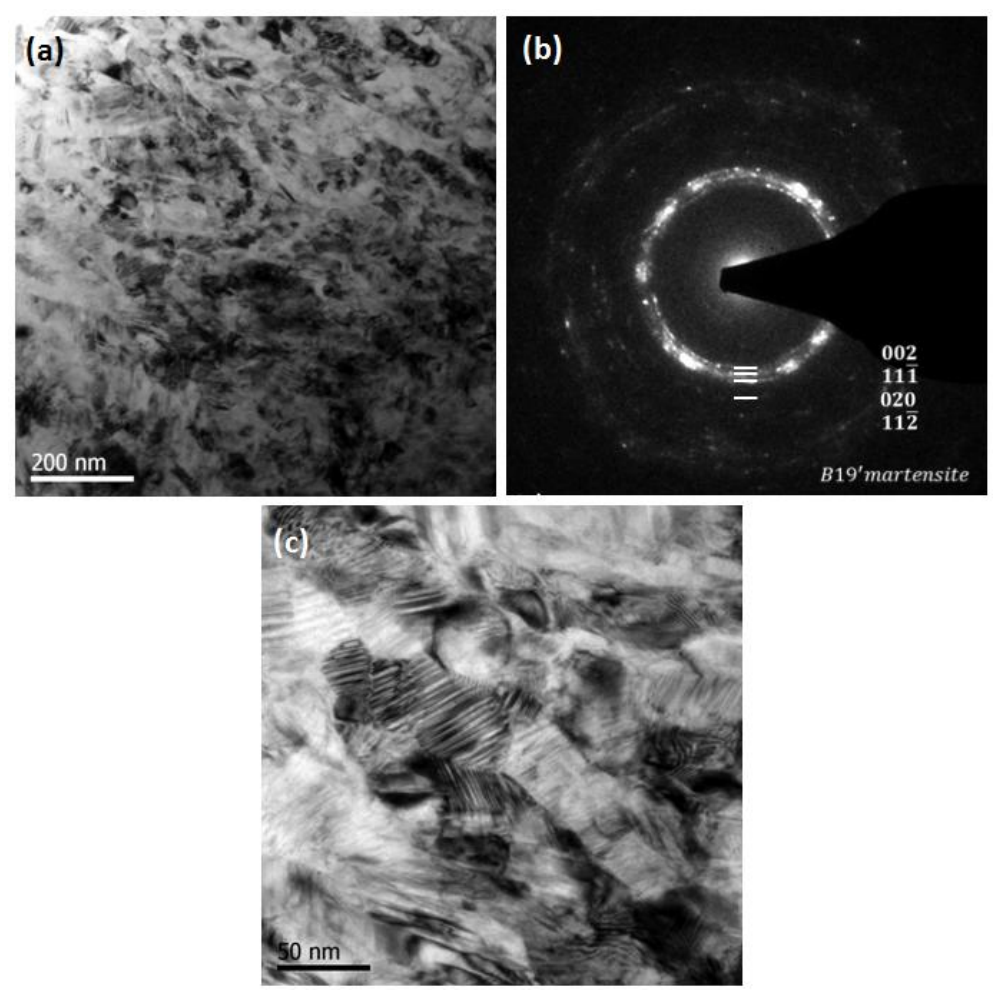

Figure 8 TEM micrographs and diffraction pattern obtained from NiTi wire-1. (a) Bright field images showing typical microstructure and (b) the corresponding SADP. (c) Higher magnification image of (a)
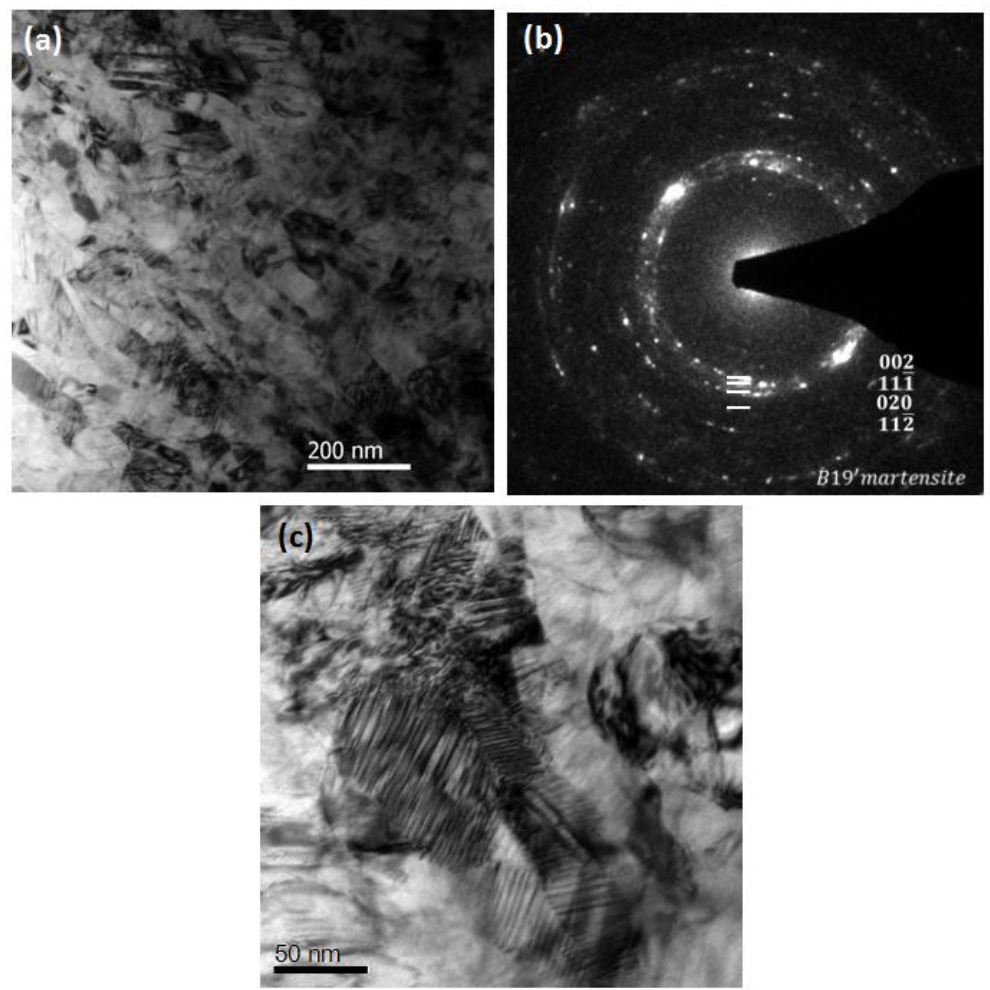

Figure 9 TEM micrographs and diffraction pattern obtained from NiTi Wire-2. (a) Bright field images showing typical microstructure and (b) the corresponding SADP indicating texture. (c) Higher magnification image of (a) 


\section{DISCUSSION}

The transformation and functional fatigue properties of NiTi SMAs are extremely sensitive to alloy chemistry, and its subsequent thermo-mechanical processing history. The wires evaluated in the present study have similar chemical composition and therefore, the variations observed in their fatigue response upon TMC can be attributed to differences in their thermo-mechanical processing history.

The TWSMS in SMAs is indicative of state of stress in the material arising from thermomechanical processing history and/or post processing stabilization treatment. It is well known [15-17] that the origin of TWSMS in SMAs is the residual internal stresses and the presence of preferably oriented martensite variants in the microstructure. The combination of these two causes deformation in martensite phase by detwinning without application of external stress, thereby leading to dissipation of stored internal energy. In the present case, both the wires show TWSMS and hence, the martensite stress plateau is absent in stress-strain plot (Fig.3). However, the magnitude of TWSMS is more in wire-2 compared to that in wire-1 (Fig.7). This clearly indicates that the orientation of martensite variants with respect to residual stress direction is more favorable in the former wire than the latter. This is further substantiated by TEM micrographs and SADP of the wires shown in Fig. 8 and 9 wherein the microstructure of wire- 1 is found to be more distorted (less favorably oriented martensite variants leading to high stored internal energy) and possess moderate texture compared to that of wire- 2 .

The driving force for phase transformation is the energy balance between Gibb's free energy of the participating phases. The change in free energy during thermoelastic martensitic transformation essentially consists of chemical and non-chemical energies. The chemical energy is reversible and is associated with the nature of bonding of the crystalline phases. The nonchemical energy in turn consists of irreversible and reversible components. The irreversible component of non-chemical energy is mainly due to dissipation of frictional energy associated with movement of interfaces during phase transformation and its interaction with defects/precipitates in the microstructure $[8,10,18]$. The reversible component of non-chemical energy is due to elastic strain energy stored in the material during elastic accommodation of strains resulting from (i) Bain strain during austenite $\rightarrow$ martensite transformation, and/or (ii) detwinning of martensite variants under external stress [8]. The formation of martensite twins is associated with elastic accommodation of Bain strain resulting from change in crystal structure during phase transformation. In presence of residual and/or external stress, detwinning of martensite variants that are favourably oriented in the stress direction takes place, and the volume fraction of detwinned martensite grows at expense of those less favourably oriented. In this process, the stored $\mathrm{E}_{\text {else }}$ of the system gets released. The variation of TWSMS seen in the two wires is, therefore, related to the magnitude of release of $\mathrm{E}_{\text {else }}$ by this process. Higher the TWSMS more is the release of stored $\mathrm{E}_{\text {else }}$ from the SMA system.

Results show that the wires used in present study have similar transformation temperatures and static mechanical properties (Figs.2 and 3). The similarity in transformation temperatures can be 
explained based on the similar chemistry of the wires. The similar tensile strengths can be attributed to mutually compensating effect of grain/variant size and texture observed in the microstructure of the wires. Lack-of/moderate texture in wire-1 is compensated by relatively smaller grain size leading to its high tensile strength. The smaller grain size also indicates that wire-1 has higher degree of retained cold work than that of wire-2.

The functional fatigue behaviour of the wires upon TMC was found to be significantly different. Wire-1 shows better stability and substantially higher fatigue life upon TMC compared to wire-2, under similar test conditions (Fig.6). Experimental results suggest that the difference in magnitude of stored $\mathrm{E}_{\mathrm{else}}$ in the wires during phase transformation is responsible for such wide variation in fatigue response. Wire- 1 is found to have a higher magnitude of stored $\mathrm{E}_{\text {else }}$ than wire2. This is evident from transformation behaviour of the two wires, wherein wire-1 requires significant under-cooling to complete the forward transformation (lower $\mathrm{M}_{\mathrm{f}}$ ) and also a tilt in the transformation curve towards left is observed (Figs.2 and 7). The thermodynamic estimation of $\mathrm{E}_{\text {else }}^{\mathrm{a}-\mathrm{m}}$ further confirms this, $\mathrm{E}_{\text {else }}^{\mathrm{a}-\mathrm{m}}$ in wire-1 being about three times of that of wire- 2 . Supporting evidence for this proposal also comes from the TEM studies wherein the lattice strain is illustrated to be higher for wire-1 than that in wire-2.

In SMAs, stored $\mathrm{E}_{\text {else }}$ in the system opposes the forward transformation and aids the reverse transformation. Therefore, high stored $\mathrm{E}_{\text {else }}$ in the material implies that less energy in terms of heat input is required for completion of reverse transformation, whereas more under-cooling is required for completion of forward transformation [8,10]. The diffused nature of forward transformation and lower $\mathrm{M}_{\mathrm{f}}$ in wire-1 (Fig.2) in comparison to wire-2 can, therefore, be explained on the basis of magnitude of stored $\mathrm{E}_{\text {else }}$ in the respective wires.

The effect of stored $\mathrm{E}_{\text {else }}$ on generation of recovery stress in the NiTi wires during TMC is clearly evident from Fig.4. Comparative study shows that at a given temperature above $\mathrm{A}_{\mathrm{s}}$, the recovery stress generated in wire-1 is 70-100 MPa more than that in wire-2. If stored $\mathrm{E}_{\text {else }}$ in the material is more, reverse transformation is facilitated and it takes place at relatively lower temperatures (Fig.5). This implies that during reverse transformation, and at a particular temperature, wire-1 has more volume fraction of transformed austenite phase compared to that in wire-2. In addition, higher stress dependence of $A_{s}$ and $A_{f}$ in wire-2 (Fig.5), increases the peak temperature further for realization of complete recovery of strain during heating cycle. As a consequence, the peak temperature that is necessary to achieve a preset peak stress in the wires during TMC differs substantially from one wire to another. Experimental results obtained in the present study show that for generation of a peak stress of $450 \mathrm{MPa}$ with $4 \%$ recovery strain, the peak temperatures in wire- 1 and wire- 2 are 115 and $130^{\circ} \mathrm{C}$ respectively. It is well known $[3,19]$ that peak temperature $\left(\mathrm{T}_{\max }\right)$ during $\mathrm{TMC}$ has significant effect on functional as well as structural fatigue behaviour of NiTi SMA thermal actuators. As the temperature increases, the damage accumulation in austenite phase during TMC accelerates [3,17-18]. This leads to not only rapid increase in RD in the wire but also, drastic decrease in fatigue life (Fig.6). It is to be noted here that decrease in RS observed during TMC does not truly reflect the RS in the material and represents only the stroke of the wire actuator at any given time. This is because the boundary within which the SMA wire 
shrinks and expands upon phase transformation is fixed. Therefore, any increase in RD (length of wire in austenite phase) gets reflected as a corresponding decrease in RS (Fig.6(a)). The change in the lower and upper stresses in the wire actuator is also the consequence of accumulation of RD in the material.

From the above, the wide variation in the fatigue behaviour observed in the two NiTi wires is related to $\mathrm{T}_{\max }$ in the wires during TMC. The results of this study show that stored $\mathrm{E}_{\text {else }}$ in NiTi wire is beneficial from thermo-mechanical fatigue behaviour point of view. Higher the stored $\mathrm{E}_{\text {else }}$ in the material, lesser is the $T_{\max }$ necessary in the wire during TMC for generation of a preset peak stress. This in turn results in a more stable stress/strain response and higher fatigue life of the SMA thermal actuator wire upon TMC.

\section{CONCLUSIONS}

The influence of stored $\mathrm{E}_{\text {else }}$ on fatigue behaviour of NiTi SMA wire thermal actuator was investigated. Two near equi-atomic NiTi wires obtained from different sources were used in the study. Thermo-mechanical fatigue tests were conducted under variable stresses in the range 150$450 \mathrm{MPa}$ with $4 \%$ recovery strain. The important conclusions from this study are as follows.

(i) Fatigue behaviour of NiTi SMA wire thermal actuators is strongly dependent on the thermo-mechanical processing history and/or post processing stabilization treatment. In spite of having similar composition, transformation temperatures and static mechanical properties, the wires can show wide variations in functional as well as structural fatigue upon TMC.

(ii) The results confirm that stored $\mathrm{E}_{\text {else }}$ in the material not only affect the transformation behaviour NiTi SMAs, but also the thermo-mechanical fatigue behaviour. Higher the stored $E_{\text {else }}$ in the material, lesser is the $T_{\max }$ necessary in the NiTi SMA wire actuator during TMC for generation of a preset peak stress and vice versa.

(iii) It has been demonstrated that high stored $\mathrm{E}_{\text {else }}$ in NiTi wire is beneficial for thermal actuator applications. Experimental data suggest that better functional stability and significant enhancement in fatigue life can be achieved by altering the stored $\mathrm{E}_{\text {else }}$ in the material through appropriate post processing treatment.

\section{ACKNLOWLEDGEMENTS}

The work presented in this study was carried out under the XI Five Year Plan Projects of CSIR, India. The authors acknowledge the contributions of D. Paul in conducting various experiments during the course of this study. The authors are thankful to Dr. B. Vidyashankar for experiments on transformation behaviour of the wires.

\section{REFERENCES}

[1] J.V. Humbeeck, Shape memory alloys: A material and a technology, Adv. Eng. Mater. 3 (2001) 837850. 
[2] F. Butera, Shape memory actuators, Adv. Mater. Process. 166 (2008) 37- 40.

[3] O.W. Bertacchini, D.C. Lagoudas, E. Patoor, Smart Structures and Materials: Active Materials: Behavior and Mechanics, in: D.C. Lagoudas (Ed.), Conf. Proc. SPIE, vol. 5053, 2003, pp. 612-624.

[4] S.K. Bhaumik, C.N. Saikrishna, K.V. Ramaiah, M.A. Venkataswamy, Understanding the fatigue behaviour of NiTiCu shape memory alloy wire thermal actuators, Key Eng. Mater. 378-379 (2008) 301-316.

[5] D.C. Lagoudas, D.A. Miller, L. Rong, P.K. Kumar, Thermomechanical fatigue of shape memory alloys, Smart Mater. Struct. 18 (2009) 085021-085033.

[6] C.N. Saikrishna, K.V. Ramaiah, S.A. Prabhu, S.K. Bhaumik, On the stability of NiTi wire during thermo-mechanical cycling, Bull. Mater. Sci. 32 (2009) 343-352.

[7] P.G. McCormick, Y. Liu, Thermodynamic analysis of the martensitic transformation in NiTi-II. Effect of transformation cycling, Acta Metall. Mater. 42 (1994) 2407-2413.

[8] R.F. Hamilton, H, Sehitoglu, Y. Chumlyakov, H.J. Maier, Stress dependence of the hysteresis in single crystal NiTi alloys, Acta Mater. 52 (2004) 3383-3402.

[9] A.R. Pelton, G.H. Huang, P. Moine, R. Sinclair, Effects of thermal cycling on microstructure and properties of Nitinol, Mater. Sci. Eng. A. 532 (2012) 130-138.

[10] R.J. Salzbrenner, M. Cohen, On the thermodynamics of thermoelastic martensitic transformations, Acta Metall. 27 (1979) 739-748.

[11] J.V. Humbeeck, R. Stalman, M. Chandrasekaran, L. Delaey, in: T.W. Duerig, K.N. Melton, D. Stockel, C.M. Wayman (Eds.), Engineering aspects of shape memory alloys, ButterworthHeinemann, London, 1990, pp. 96-105.

[12] J. Bhagyaraj, K.V. Ramaiah, C.N. Saikrishna, Gouthama, S.K. Bhaumik, Microstructural investigation of shape memory annealed Ni-Ti-Cu wire, Conf. Proc. of Electron Microscopy \& Allied Fields - XXX Annual Meeting of EMSI, January 17- 19, 2009, Jhansi, India, pp. 18-19.

[13] H.C. Ling, R. Kaplow, Stress-induced shape changes and shape memory in the R and martensite transformations in equiatiomic NiTi, Met. Trans. 12A (1981) 2101-2111.

[14] R. Delville, B. Malard, J. Pilch, P. Sittner, D. Schryvers, Microstructure changes during nonconventional heat treatment of thin $\mathrm{Ni}-\mathrm{Ti}$ wires by pulsed electric current studied by transmission electron microscopy, Acta Mater. 58 (2010) 4503-4515.

[15] J. Perkins, G.R. Edwards, C.R. Such, J.M. Johnson, R.R. Allen, Shape memory effects in alloys, Plenum Press, New York, 1975, pp. 273-303.

[16] Y. Liu, P.G. McCormick, Factors influencing the development of two way shape memory in NiTi, Acta Mater. 38 (1990) 1321-1326.

[17] J. Perkins, R.O. Sponholz, Stress-induced martensitic transformation cycling and two-way shape memory training in Cu-Zn-Al alloys, Metall. Trans. A 15 (1984) 313-321.

[18] E. Hornbogen, Thermo-mechanical fatigue of shape memory alloys, J. Mater. Sci., 39 (2004) 385399.

[19] S.K. Bhaumik, C.N. Saikrishna, K.V. Ramaiah, Characteristic behaviour of NiTi SMA wire undergoing thermo-mechanical cyclic loading, Proc. $6^{\text {th }}$ ISSS Inter. conf. on Smart Mater. Struct. \& Sys., January 4-7, 2012, IISc, Bangalore, India, Paper No.4M. 